\title{
The End of East-West Divergence in European Life Expectancies? An Introduction to the Special Issue
}

\author{
France Meslé $^{1} \cdot J_{\text {Jacques Vallin }}^{1}$
}

Published online: 21 November 2017

(C) Springer Science+Business Media B.V., part of Springer Nature 2017

\section{Introduction}

Human populations have always searched for ways to ward off disease and death, but it was only after many thousands of years that they first became truly effective at reducing famines, epidemics and other infectious diseases. Starting in Northwest Europe in the eighteenth century, progress in achieving ever higher life expectancies gradually spread across the entire world. After Pasteur's revolution, followed by the discovery of antibiotics, progress accelerated so fast that life expectancy was widely expected to reach a ceiling in all countries. By the end of the 1950s, nobody really doubted this, especially since social security systems and the WHO were there to ensure the global accomplishment of this historical change. In the framework of the most popular demographic theory, the demographic transition theory (Notestein 1945), Omran (1971) developed his three-age ${ }^{1}$ epidemiologic transition theory to explain both the extraordinary rise of life expectancy and the subsequent slowdown due to the biological limits of human longevity, which had already been predicted in the early 1950s by other demographers such as Vincent (1951) and BourgeoisPichat (1952). At that time, the United Nations' World Population Prospects assumed there would be a general convergence towards the supposed maximum of life expectancy in all countries.

Since then, major events have occurred that contradict this idealistic scenario. Unpredictable events have unfolded, for the better and for the worse. On the upside, although the slowing progress in life expectancy in the 1960s seemed to prove that

\footnotetext{
1 Starting with "age of pestilence and famine" and ending with "age of degenerative diseases and manmade diseases" via a transitionary "age of receding pandemics".
}

France Meslé

mesle@ined.fr

1 INED, Paris, France 
most advanced countries were approaching the maximum, the 1970s brought a completely new perspective with the successful fight against cardiovascular diseases - which, until then, had been considered as degenerative and not amenable to medical treatment. Life expectancy started rising again in all Western industrialized countries and offered the promise of breaking its supposed limits. However, on the downside, it also became clear that not all countries could follow this new promising direction, since communist regimes in Central and Eastern Europe proved unable to benefit from the cardiovascular revolution, despite their success in catching up with Western countries in the fight against infectious diseases. And finally, to make things worse, the spectacular upward trends in life expectancy observed after WWII in many developing countries were suddenly halted by the world economic crisis of the 1970s and, soon afterwards, brutally reversed by the AIDS epidemic. Consequently, at the end of the twentieth century, the epidemiologic transition theory was invalidated, general convergence was no longer on the agenda, and health inequalities became greater than ever. New theoretical approaches, including the concept of divergence-convergence cycles, were proposed to take better account of these diverse historical trajectories. Specific attention was paid to the impressive East-West divergence. In recent decades, some signs of convergence have emerged. Is this a sustainable new trend? The articles in this special issue seek to answer this question, relying on detailed and reliable data and analyses of causes of death.

\section{From Omran's Epidemiologic Transition Theory to the Divergence- Convergence Framework}

Beyond first attempts to improve Omran's theory by adding one or two more steps to his three original "ages" (Omran 1983, 1998; Olshansky and Ault 1986; Rogers and Hackenberg 1987), several authors argued that the epidemiologic theory was too strongly influenced by the rapid success of antibiotics in vanquishing infectious diseases and therefore failed to take into account the non-medical aspects of health development. They thus proposed to reconstruct the theory around a more general concept of health transition (Frenk et al. 1991). We (Vallin and Meslé 2004) have tried to interpret historical trends more precisely by introducing a central paradigm: any new major innovative health tool results first in a divergence process. This is relevant because some countries are better prepared than others, in that their economies or political and social structures are in a stronger position to implement this tool for the benefit of the whole population. Naturally, after some delay, the laggards may adapt and catch up with the pioneers. Thus, the full story of the health transition may be seen through a succession of divergence-convergence cycles arising from the availability of new health tools and their varying speeds of implementation (Vallin and Meslé 2004). Furthermore, the complexity of the current diversity observed across the world is even more understandable when two additional possibilities are considered. Firstly, the succession of cycles is not necessarily well ordered: some countries may initiate a new cycle well before all other countries have ended the previous one. Secondly, an ongoing phase of 
progress may be interrupted at any time when the economic, social or political conditions that made it possible are disrupted for any reason.

Historically, two major cycles of divergence-convergence can be easily identified, and a potential third is developing today. The success in combating infectious diseases produced a first divergence between North-Western European countries and the rest of Europe, then later between the world's so-called developed and underdeveloped countries. However, in the period after WWII when the WHO was created, the developing countries-most of them now liberated from colonial dependence-began to reduce the life expectancy gap, achieving faster gains than those ever recorded in developed countries (Preston 1976). In addition to their political and economic empowerment that enabled them to mobilize the means for health improvement, they also benefited from powerful tools such as vaccines and antibiotics that had already been developed in Europe or North America. Nevertheless, not all developing countries were able to catch up with the pioneers due to a series of dramatic disruptive events that were either economic (world economic crisis and structural adjustment plans), political (internal conflicts and civil wars) or epidemiological (like the AIDS epidemic in Africa) (Pison et al. 1989; Timaeus 2007). By the end of the twentieth century, these events had given rise to the widest worldwide range of life expectancies ever observed, despite the fact that many developing countries had almost caught up with the most advanced ones.

At the same time, the second half of the twentieth century was marked by a second cycle that began in the mid-1960s with the spectacular divergence between Western developed countries and Central and Eastern Europe. While the West had entered the cardiovascular revolution (Vallin and Mesle 2001), the other regions had not only failed to follow suit, but had also failed to halt the rise in so-called man-made diseases (Omran 1971) brought about by the negative side effects of the Industrial Revolution and its societal consequences, such as violent deaths, alcoholism, smoking and drug addiction. This East-West divergence in European life expectancies is a major feature of European demographic trends at the end of the twentieth century. In 1965, life expectancy in the USSR was just 3 years behind that of the most advanced Western region (Northern Europe): 65.4 versus 68.4 years, yet 30 years later the gap between USSR and the most advanced Western region (Southern Europe) was more than 15 years: 59.2 versus 74.4 years. After the fall of the Berlin wall, this dramatic divergence started to give way to a new convergence-but with variations in timing: Poland and the Czech Republic paved the way, while Russia and Ukraine followed very late, if at all.

A third cycle is probably starting in the most advanced countries. It is already visible among females, who are much more advanced than males in terms of life expectancy where a clear gender division is already visible with females having much higher life expectancy than males. In the 1980s, female life expectancy at age 60 appeared to be slowing down in some countries, such as the USA and the Netherlands, but was still increasing quickly in others such as Japan and France (Meslé and Vallin 2006). Such divergence could be the result of different ways of caring for the elderly. However, the background and reasons for this need to be explored further but go beyond the focus of this special issue. 


\section{The Second Divergence-Convergence Cycle: The East-West Divide}

Many authors (e.g. Davis 1956; Stolnitz 1965; Mc Keown et al. 1972) focused their attention on the first divergence-convergence cycle-in which NorthWestern European countries differed from the rest of Europe and, later, all industrialized countries contrasted with the less developed world-before the process was finally described by Omran's epidemiologic transition theory. This was very clearly built around the fight against infectious diseases and infant mortality, for which the necessary tools became available at different times in different parts of the world.

According to Omran's theory, life expectancy would slow down very soon in the most advanced countries. In these regions of the world, the transition was supposedly nearing completion and life expectancy was reaching its ceiling due to the irreducible nature of the remaining causes of death and the expected expansion of man-made diseases. Indeed, life expectancies in all industrialized countries (except Japan) ceased to increase for a while in the late 1950s or early 1960s. ${ }^{2}$ However, very soon afterwards, many innovative tools arrived and changes in health behaviour occurred, all of which proved effective in reducing cardiovascular diseases, thus completely gainsaying Omran's prediction. However, whereas the brief pause in the 1960s was followed by a robust further upward trend in all Western countries, the Eastern European countries, which had successfully caught up with them, now experienced stagnation or even a decline in their life expectancies. This divergence was striking, particularly for men (Fig. 1).

The greatest divergence can be seen between Japan, the most advanced country in the "Western" world, and Russia, with the former progressing seamlessly from the control of infectious diseases to the control of cardiovascular diseases, with no pause in its upward life expectancy trend. Japan is probably the country that most quickly and extensively took advantage of new approaches to cardiovascular disease. The situation in Russia, on the other hand, deteriorated seriously after Omran's epidemiologic transition was completed. Whereas male life expectancy in Japan rose from 68 to 78.5 years between 1965 and 2005, it fell from 64 to 59 years in Russia over the same period. Although the contrast between other countries is less striking, the trends observed in the Western countries (here represented by France and the USA) are all significantly better than those of the Eastern European countries until the early 1990s, when Central Europe ceased diverging. The divergence continued to widen for the countries of the former Soviet Union, however, represented here by Russia and Ukraine. Once these two countries had weathered the major upheavals resulting from Gorbachev's anti-alcohol campaign and the socio-economic shock of shifting to a form of market economy (Meslé et al. 1998; Meslé and Vallin 2012), the male life expectancy trends continued until around 2004-2005 the downward movement initiated in 1965.

\footnotetext{
${ }^{2}$ Although there are clear differences between men and women, we focus our attention on male life expectancy in the introduction. Gender differences will, however, be covered and addressed in several of the articles included in this special issue.
} 


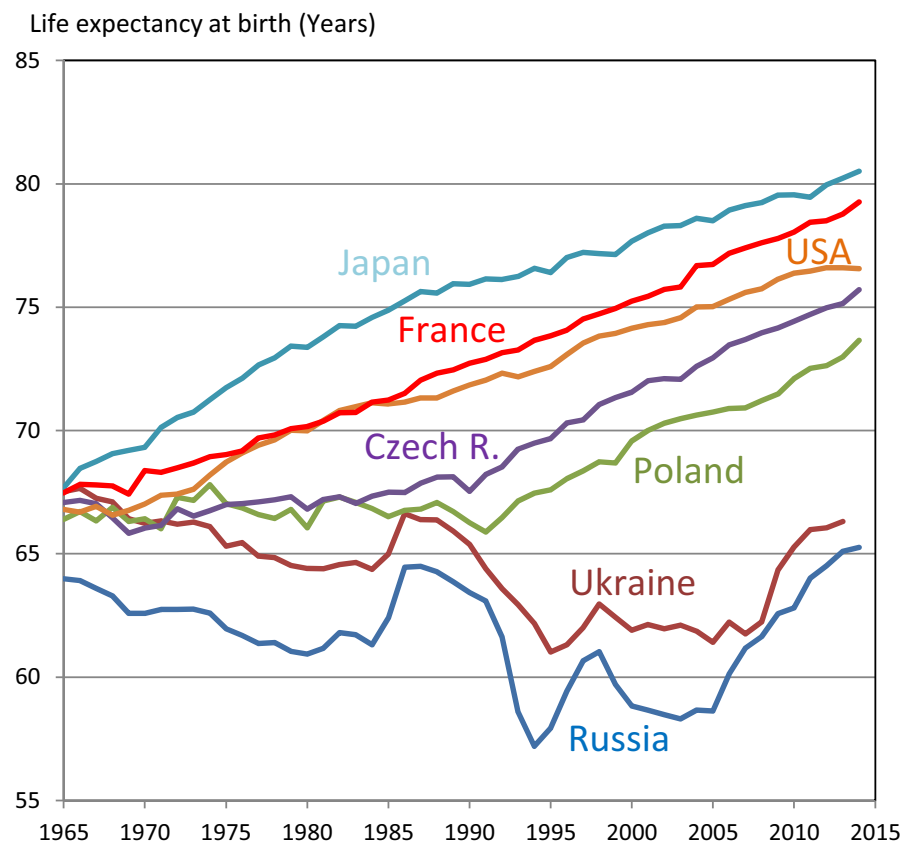

Fig. 1 Male life expectancy in selected industrial countries, 1965-2014 (Reproduced with permission from Vallin and Meslé (2004) data extended to 2014 by the authors)

In addition to the major victory over man-made diseases, which Omran identified as typical of the third age in his epidemiologic transition, the second stage of health transition is mainly a period of declining mortality from cardiovascular diseases, classified by Omran among the degenerative diseases that are difficult to reduce. And this is true in both divergence and convergence waves.

A clear picture of the dominant role of cardiovascular disease can be gained by examining the respective contributions of changes in death rates by age and cause of death to changes in life expectancy between 1965 and 2005 (Fig. 2).

Figure 2 compares the components of life expectancy gains or losses in France and Russia over the entire 1965-2005 period. The only feature common to the two countries is the positive role of declining infant mortality, which accounts for a 1.5year increase in life expectancy in both countries. However, most of the French life expectancy gains (7.9 years) are due to the decrease in adult cardiovascular mortality, which alone accounts for 3.6 years of life expectancy gains. During this period, France clearly benefited from a drop in both man-made and cardiovascular diseases which, according to Omran's theory, were the two factors that will cause life expectancy to level off in the third age of the epidemiologic transition.

In contrast, cardiovascular mortality in Russia increased at all ages, taking a total of 3.3 years off male life expectancy. At the same time, two further years of life were lost from an increase in violent deaths, a category that includes alcohol poisoning as well as traffic accidents, suicide, homicide. Russia is thus a country that exemplifies, in its most extreme form, the features of Omran's third age: the 


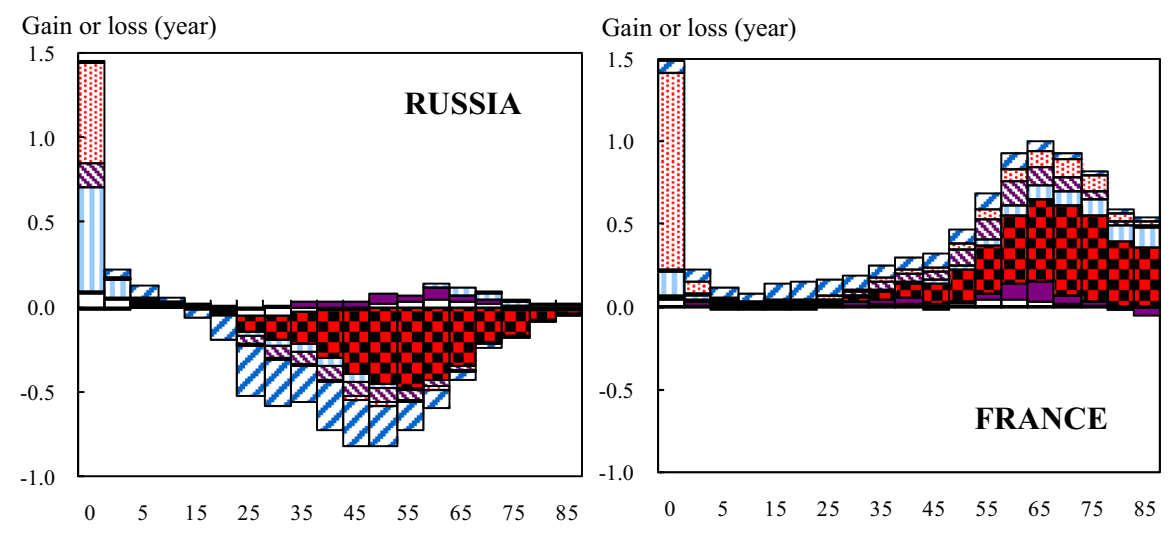

ÐExternal causes $\quad$ O Other diseases

Q Digestive diseases $\square$ Respiratory diseases

- Circulatory diseases $\boldsymbol{a}$ Neoplasms

$\square$ Infectious diseases

Fig. 2 Contributions of mortality changes by age and cause to male life expectancy at birth: gains and losses in Russia and France (1965-2005) (Reproduced with permission from: Vallin and Meslé (2004) data extended to 2005 by the authors)

pandemic of degenerative and man-made diseases has been such that the benefits of lower infectious mortality have been completely cancelled out. The same trends may be observed in the other European countries of the former Soviet Union, such as Ukraine (Meslé and Vallin 2012), Belarus (Grigoriev et al. 2010) and also the Baltic countries (Jasilionis et al. 2011) —at least until the late 1990s.

The second part of the cycle (convergence) occurred first in the Central European countries (Fig. 1). The Czech Republic and Poland, in particular, have been making uninterrupted progress for almost a quarter century now. The Czech Republic pioneered the trend in the late 1980s and was soon followed by Poland, Slovakia and Hungary (not shown in Fig. 1). Romania and Bulgaria followed a few years later (Meslé 2004). Over the last 25 years, the pace of increase in life expectancy has been faster in the Czech Republic and Poland than in the USA, but this is more a result of the recent slowdown in the USA than of a very fast increase in the two Central European countries, where progress is quite similar to that of France and Japan. It is impossible to predict whether the Czech Republic will catch up with France and Japan in the near future, and Poland even less so. The reason for this could be, however, that a third cycle of divergence-convergence has already begun to contrast the steady progress in France and Japan with the slowdown of the USA.

By contrast, the case of Ukraine and Russia is somewhat paradoxical. Although the reversal in positive trends started much later, these countries succeeded in increasing their life expectancy much more rapidly than did Central Europe after 2005. In just 7 years (2005-2012), Russian males gained almost 6 years of life expectancy and Ukrainian males almost 5 years, while Czech and Polish men gain only 2 years over the same period. However, in the last 2 years, Russian and 
Ukrainian gains seem to have slowed down to a level which is still lower than the Czech and Polish levels in the early 1990s (Fig. 1). Indeed, the convergence movement has started, although it is quite different in Central Europe and the former USSR. Nonetheless, it is far from certain that they will catch up with Western countries in the coming years.

\section{The Crucial Importance of Building Coherent Time Series of Deaths by Cause}

To get to know more about the sustainability of the trend reversal, an in-depth analysis of cause-of-death trends is required. Unfortunately, causes of death are neither easily nor commonly explored. This is largely attributable to the huge difficulty caused by the periodic disruptions in cause-of-death statistics resulting from changes in cause-of-death classifications. Several authors have proposed different ways to harmonize series (Janssen and Kunst 2004; Rey et al. 2011; Stegen et al. 2014), but these methods never yield continuous time series in sufficient detail, fully classified by age and sex. How can a coherent time series of deaths by cause be reconstructed based on a constant classification? This endeavour was first started with the French data by developing a method to produce a posteriori bridge coding, which makes it possible to reclassify under a new classification deaths previously classified under an old one. Thus, by successively bridging each classification in use during one period with the new one covering the next period, coherent French time series of deaths by cause have been reconstructed from 1925 (the first year for which France produced national cause-of-death statistics by sex and age) to 1978- the last year covered by the 8th revision of the International Classification of Diseases (ICD-8) - in accordance with the detailed list of ICD-8 (Vallin and Mesle 1988). ICD-8 was later bridged to ICD-9 (Meslé and Vallin 1996), and longer series (entirely covered by ICD-9) were made available until 1999, the year before ICD-10 took effect. Further efforts for Europe were developed afterwards as will be explained below.

This method for making cause-of-death data comparable over time also facilitates international comparisons. In the 1980s, it became crucial to understand the severe health crisis that had been affecting the USSR since the mid-1960s the method developed for France was successively applied to the different countries of the former USSR (Meslé et al. 1992). ${ }^{3}$ Russia was the first (Shkolnikov et al. 1996), then Ukraine (Meslé and Vallin 2012), the three Baltic countries (Hertrich and Meslé 1999), Belarus (Grigoriev et al. 2012), Georgia and Armenia (Duthé et al. 2010) and, finally, Moldova (Penina forthcoming). This initial project was developed further in multiple national reconstruction projects including East and West Germany, the Czech Republic and Poland that are all included in this special issue.

\footnotetext{
3 The initiative was taken in an international collaborative project between the French Institute for Demographic Studies (INED) and the Moscow Center for Demography and Human Ecology and further strengthened and expanded in the framework of solid cooperation between INED and the Max Planck Institute for Demographic Research (MPIDR), supported by several research grants.
} 


\section{Could Eastern Countries Catch Up with Western Countries in the Near Future?}

The divergence process between Eastern and Western countries has already been studied extensively (Hertzman et al. 1995; Vallin and Meslé 2001; Moser et al. 2005). The emergence of innovative tools to combat cardiovascular diseases and man-made diseases caused an initial divergence whereby the countries best able to use these new resources resumed their upward trends after exhausting all the benefits that could be drawn from the previous stage of infectious disease control. Some countries, led by Japan and followed in short order by almost all the Western industrial countries, were quick to maximize the benefits of new therapeutic technologies and, perhaps even more so, of new approaches for preventing cardiovascular disease. This was not the case in other countries, particularly in Central and Eastern Europe, where little progress was made over a quarter of a century. The failure of the Communist countries was most likely due to a double disadvantage. First, the economic difficulties resulting from the arms and space races slowed the diffusion of the expensive technologies required to treat the most serious cardiovascular diseases (Sidel 1981; Woolhandler and Himmelstein 1985; Field 1995). Second, while effective at controlling infectious diseases with vaccinations and antibiotics, their over-centralized political and social systems fell short when individual responsibility mattered in achieving the necessary behavioural changes in diet and life style.

The current phase of convergence is more complex (Leon 2011; Mackenbach 2013; Grigoriev et al. 2014; Shkolnikov et al. 2013). The fall of communism resulted in two major changes: brutal transition to new political and socio-economic regimes and the opening of national borders. Both had a positive and negative impact on the health status of populations and on life expectancy. In particular, these changes increased poverty and vulnerability among a large share of the population. However, the introduction of new medical techniques, the implementation of new health systems and the adoption of new individual behaviours led to major health and life expectancy improvements. They undoubtedly reflect massive progress in terms of cardiovascular and man-made diseases (Grigoriev et al. 2010; Jasilionis et al. 2011), but many aspects require more explanation. For that reason, this special issue of the European Journal of Population is devoted to the complexity of the convergence processes observed in Central and Eastern Europe. Even if - for a greater understanding of the ongoing changes - most of the papers published here more or less embrace the whole cycle of divergence-convergence, our focus is primarily on disentangling the complexity of recent trends in order to discuss the possibility that Eastern European countries will close the gap with Western countries in the foreseeable future.

To clarify the background material used in this perspective, it was important to begin this collection of articles with a rapid presentation of the method for reconstructing coherent time series of deaths by cause, paying particular attention to the noticeable improvements achieved collectively through the international collaboration mentioned above. The first article, by Markéta Pechholdová, Carlo 
Giovanni Camarda, France Meslé and Jacques Vallin, summarizes the general principles of the method, originally developed to reconstruct time series for France from 1925 to 1999 , specifically by matching them to the detailed list of the 9th revision of the WHO International Classification of Diseases (ICD-9). To accomplish this, we successively bridged a posteriori the five versions of the ICD in use during that period. The article then reports on the most important recent methodological improvements to the method, either to set correspondence tables between items of two successive classifications or to build the fundamental associations of items and finally to compute transition coefficients.

Each of the subsequent papers then deals with a specific piece of the puzzle that represents the complete study of the cycle of divergence-convergence in life expectancy between East and West, all focusing primarily on the following two questions: Is the East-West divergence ending? And how?

The second article, by Agnieszka Fihel and Markéta Pechholdová, focuses on two post-Communist countries, the Czech Republic and Poland, which were the first to record a sudden and complete shift in life expectancy trends, and it explains how life expectancy increased by more than 6 years from 1991 to 2013 for both sexes. In particular, it demonstrates the crucial importance of the reduction in diseases of the circulatory system. These changes narrowed these countries' life expectancy gap with respect to France but also give an indication of what will happen to Russia in years to come. The authors underline the most important determinants for this new phase of progress: the reorientation of health policies; the emergence of nongovernmental organizations; shifts in human behaviours and attitudes; and changes in the structure of education.

The third paper, by Olga Penina, focuses more specifically on alcohol-related causes of death, which are the key man-made diseases contributing to the East-West divergence. It underlines Moldova's highly specific situation in this respect. Indeed, in most Soviet countries (especially, Russia, Ukraine and Belarus), the Nordic type of alcohol consumption led to massive mortality resulting from acute alcoholism and other sudden alcohol-related deaths. Moldovan drinking habits are quite different in that they are much closer to those of the Mediterranean drinking culture, which results in very high mortality from liver cirrhosis. A second Moldovan specificity is that women are affected by this cause of death as much as men. The author concludes with suggestions for improving Moldovan anti-alcohol policy accordingly.

The fourth paper, by Pavel Grigoriev and Markéta Pechholdová, deals with an almost perfect natural experiment: the case of East-West contrasts in Germany, before and after the fall of the Berlin Wall. How did trends diverge and then converge? What was the role of German reunification in the convergence process in light of evolving long-term mortality trends by cause of death? The authors identify three distinct processes taking place in East Germany around the time of reunification: a sustainable reduction in mortality, which started before reunification; a temporary increase in mortality in 1990-1991; and a reunification-driven process of convergence. Mortality improvements observed in the GDR since the 1980s might be interpreted as the first signs of a cardiovascular revolution. Shifts in individual behaviour likely started before reunification, whereas real progress in 
medical care occurred later with the implementation of the Western system of health care. Therefore, German reunification per se did not initiate the convergence process but rather reinforced and accelerated trends that were already apparent.

Finally, the fifth paper, by Sergei Timonin, Inna Danilova, Evgeny Andreev, and Vladimir M. Shkolnikov, views Russia from a completely different angle: how can internal geographical differences in mortality by cause of death be observed and interpreted in this large country? To understand the rise of Russian life expectancy since 2005 , it is important to take into account regional diversity and its changes. Has the decrease in inter-regional diversity contributed to the rise in national life expectancy? And what was the role of regional differences in age- and causepatterns of mortality? The authors pursue those questions by applying decomposition techniques for examining the age- and cause-specific changes in disparities in life expectancy at the sub-national level for the recent period of health improvement in Russia.

While none of these five empirical articles are able to offer a comprehensive answer to our opening question about an actual convergence of Central and Eastern Europe towards the most advanced Western countries, each of them contributes important pieces of the puzzle. Agniezska Fihel and Markéta Pechholdová point out the crucial role of reorienting health policies and of changes in the structure of education. Olga Penina underlines the specific role of unexpected features of alcohol consumption in Moldova. Pavel Grigoriev and Markéta Pechholdová indicate the role of German reunification as a powerful acceleration factor, and Sergei Timonin and his co-authors give a clear idea of the scale of internal diversity in a large country such as Russia, emphasizing the particular role played by its two megacities, Moscow and St-Petersburg. In total, although it is obvious that huge and favourable changes have characterized a new historical phase of rapid progress in Central Europe since 1991 and in Eastern Europe since 2005, the extent to which these parts of Europe are on a path towards catching up with Western countries remains unclear. In the case of Central Europe, however, it seems that the gap could close quite soon with the USA but not with France or Japan. This is not because Central Europe has not yet completed its second step in the health transition (the cardiovascular revolution), but because the third step in the health transitionwhich has already begun-is introducing a new divergence between Japan and France on the one hand and the USA on the other. Although recent progress has been even faster in Russia and Ukraine than in Central Europe, its sustainability remains open to question.

The countries of Central and Eastern Europe face different future challenges. For countries like Poland or Czech Republic, the main uncertainty no longer concerns cardiovascular and/or man-made diseases at working ages but rather their capacity to follow Western countries like France or Japan which are starting to reduce mortality at old and very old ages. This will call for further adaptation of their health systems to address the needs of the elderly population, in terms of both living arrangements and health care provision. In countries like Russia or Moldova, a lot is still to be done in terms of cardiovascular diseases in middle-aged adults and, more generally, in terms of man-made diseases like alcoholism and violence, although their attention must also focus on the future needs of the elderly. 
Beyond these inter-country differences, special attention must also be paid to infra-national inequalities (gender, region, education, socio-economic status, etc.). The divergence-convergence framework can be used at sub-national level. Even within the same country, some sections of the population will benefit more rapidly from a new innovation because they are more educated or live in a better-equipped region, or they have less risky health behaviours. Life expectancy will initially diverge between these different groups before some convergence occurs when the innovation spreads across the whole population. One paper in this special issue gives some pieces on the topic for Russia, but levels and trends in inequalities are still largely unexplored and need further explanation under this theoretical framework.

Acknowledgements This research was supported by the French Institute for Demographic Studies (INED) and the Max Planck Institute for Demographic Research (MPIDR). This collaboration was supported by two research grants: Project ANR-12-FRAL-0003-01 "Diverging Trends in Mortality and Future Health Challenges" (DIMOCHA) and AXA project "Mortality Divergence and Causes of Death" (MODICOD).

\section{References}

Bourgeois-Pichat, J. (1952). Essai sur la mortalité biologique de l'homme. Population, 7(3), 381-394.

Davis, Kingsley. (1956). The amazing decline of mortality in underdeveloped areas. American Economic Review, 46, 305-318.

Duthé, G., Badurashvili, I., Kuyumjyan, K., Meslé, F., \& Vallin, J. (2010). Mortality in the Caucasus: An attempt to re-estimate recent mortality trends in Armenia and Georgia. Demographic Research, 22(23), 691-732.

Field, M. G. (1995). The health crisis in the former Soviet Union: A report from the "post-war" zone. Social Science and Medicine, 41(11), 1469-1478.

Frenk, J., Bobadilla, J. L., Stern, C., Frejka, T., \& Lozano, R. (1991). Elements for a theory of the health transition. Health Transition Review, 1(1), 21-38.

Grigoriev, P., Meslé, F., Shkolnikov, V., Andreev, E., Fihel, A., Pechholdová, M., et al. (2014). The recent mortality decline in Russia: Beginning of the cardiovascular revolution? Population and Development Review, 40(1), 107-129.

Grigoriev, P., Meslé, F., \& Vallin, J. (2012). Reconstruction of continuous time series of mortality by cause of death in Belarus, 1965-2010. Working paper WP-2012-023. Rostock: MPIDR.

Grigoriev, P., Shkolnikov, V. M., Andreev, E. M., Jasilionis, D., Jdanov, D. A., Meslé, F., et al. (2010). Possible explanations of the divergence in recent mortality trends among Belarus, Lithuania, and Russia. European Journal of Population, 26(3), 245-274.

Hertrich, V., \& Meslé, F. (1999). The health crisis in the Baltic countries: A common and varied experience. In European Population Conference, La Haye. Paris: INED, August 30-September 3, 1999.

Hertzman, C., Kelly, S., \& Bobak, M. (1995). East west life expectancy gap in Europe. Environmental and non-environmental determinants. Dordrecht: Kluwer.

Janssen, F., \& Kunst, A. E. (2004). ICD coding changes and discontinuities in trends in cause-specific mortality in six European countries, 1950-1999. Bulletin of the World Health Organization, 82(12), 904-913.

Jasilionis, D., Meslé, F., Shkolnikov, V. M., \& Vallin, J. (2011). Recent life expectancy divergence in Baltic countries. European Journal of Population, 27(4), 403-431.

Leon, D. A. (2011). Trends in European life expectancy: A salutary view. International Journal of Epidemiology, 2, 271-277.

Mackenbach, J. P. (2013). Convergence and divergence of life expectancy in Europe: A centennial view. European Journal of Epidemiology, 28(3), 229-240. 
Mc Keown, T., Brown, R. G., \& Record, R. G. (1972). An interpretation of the modern rise of population. Population Studies, 26(3), 345-382.

Meslé, F. (2004). Mortality in Central and Eastern Europe: Long-term trends and recent upturns. Demographic Research, SC(2):46-70. (Determinants of diverging trends in mortality).

Meslé, F., \& Vallin, J. (1996). Reconstructing long-term series of causes of death: The case of France. Historical Methods, a Journal of Quantitative and Interdisciplinary History, 29(2), 1-26.

Meslé, F., \& Vallin, J. (2006). Diverging trends in female old-age mortality: The United States and the Netherlands versus France and Japan. Population and Development Review, 32(1), 123-145.

Meslé, F., \& Vallin, J. (2012). Mortality and causes of death in 20th century Ukraine. Dordrecht: Springer.

Meslé, F., Shkolnikov, V. M., \& Vallin, J. (1992). Mortality by cause in the USSR in 1970-1987: The reconstruction of time series. European Journal of Population, 8(4), 281-308.

Meslé, F., Vallin, J., \& Shkolnikov, V. M. (1998). Reversal of mortality decline: The case of contemporary Russia. World Health Statistics Quarterly/Rapport trimestriel de statistiques sanitaires, 51(2-4), 191-206.

Moser, K., Shkolnikov, V., \& Leon, D. A. (2005). World mortality 1950-2000: Divergence replaces convergence from the late 1980s. Bulletin of the World Health Organization, 83(3), 202-209.

Notestein, F. (1945). Population, the long view. In T. Schultz (Ed.), Food for the world (pp. 36-57). Chicago: University of Chicago Press.

Olshansky, S. J., \& Ault, A. B. (1986). The fourth stage of the epidemiologic transition: The age of delayed degenerative diseases. The Milbank Quarterly, 64(3), 355-391.

Omran, A. R. (1971). The epidemiologic transition: A theory of the epidemiology of population change. The Milbank Memorial Fund Quarterly, 49(4), 509-538.

Omran, A. R. (1983). The epidemiological transition theory: A preliminary update. Journal of Tropical Pediatrics, 29, 305-316.

Omran, A. R. (1998). The epidemiologic transition theory revisited thirty years later. World Health Statistics Quarterly, 51(2-3-4), 99-119. (Historical epidemiology: Mortality decline, and old and new transitions in health, Special Issue ed. O. Frank).

Penina, O. (forthcoming). Reconstruction of coherent time series of deaths by cause in Moldova, 1965-2014. Working paper. Paris INED.

Pison, G., van de Walle, É., \& Sala-Diakanda, M. (1989). Mortalité et société en Afrique au sud du Sahara. Paris: INED (Cahier no 124).

Preston, S. H. (1976). Mortality patterns in national populations. With special reference to recorded causes of death. New York: Academic Press.

Rey, G., Aouba, A., Pavillon, G., Hoffmann, R., Plug, I., Westerling, R., et al. (2011). Cause-specific mortality time series analysis: A general method to detect and correct for abrupt data production changes. Population Health Metrics, 9, 52.

Rogers, R. G., \& Hackenberg, R. (1987). Extending epidemiologic transition theory. Social Biology, 34, 234-243.

Shkolnikov, V., Meslé, F., \& Vallin, J. (1996). Health crisis in Russia. I. Recent trends in life expectancy and causes of deaths from 1970 to 1993. II. Changes in causes of death, a comparison with France and England and Wales, from 1970 to 1993. Population, an English Selection, 8, 155-190.

Shkolnikov, V. M., Andreev, E. M., McKee, M., \& Leon, D. A. (2013). Components and possible determinants of decrease in Russian mortality in 2004-2010. Demographic Research, 28(32), 917-950.

Sidel, V. W. (1981). Buying death with taxes: Impact of arms race on health care. In R. Adams \& S. Culleu (Eds.), The final epidemic (pp. 40-44). Chicago: University of Chicago Press.

Stegen, R. H. M. V. D., Koren, L. P. H., Harteloh, P. P. M., Kardaun, W. P. F., \& Janssen, F. (2014). A novel time series approach to bridge coding changes with a consistent solution across causes of death. European Journal of Population, 30(3), 317-335.

Stolnitz, G. H. (1965). Recent mortality trends in Latin America, Asia and Africa. Population Studies, 19, $117-138$.

Timaeus, I. (2007). Impact of HIV on mortality in Southern Africa: Evidence from demographic surveillance. In M Caraël, J. R. Glynn (Eds.), HIV, Resurgent Infections and Population Change in Africa (pp. 229-244). Dordrecht: IUSSP and Springer (International Studies in Population).

Vallin, J., \& Meslé, F. (1988). Les causes de décès en France de 1925 à 1978. Paris: INED and PUF (Travaux et Documents, Cahier no 115). 
Vallin, J., \& Meslé, F. (2001), Trends in mortality in Europe since 1950: Age-, sex- and cause-specific mortality. In J. Vallin, F. Meslé et al. (Eds.), Trends in mortality and differential mortality (pp. 31-186). Strasbourg: Council of Europe Publishing (Population Studies no 36).

Vallin, J., \& Meslé, F. (2004). Convergences and divergences in mortality. A new approach to health transition. Demographic Research, SC(2):12-43. (Determinants of Diverging Trends in Mortality).

Vincent, P. (1951). La mortalité des vieillards. Population, 6(2), 181-204.

Woolhandler, S., \& Himmelstein, D. U. (1985). Militarism and mortality: An international analysis of arms spending and infant death rates. The Lancet, 325(8442), 1375-1378. 